УДК 615.32:582.734.4:581.45:542.47(571.6)

\title{
ВЛИЯНИЕ СПОСОБОВ СУШКИ ЛИСТЬЕВ ЗЕМЛЯНИКИ ВОСТОЧНОЙ (FRAGARIA ORIENTALIS LOSINSK.) НA СОДЕРЖАНИЕ БИОЛОГИЧЕСКИ
}

\section{АКТИВНЫХ ВЕЩЕСТВ}

(ㄱ Г.Я. Мечикова*, Т.А. Степанова, Н.В. Матющенко

Дальневосточный государственный медицинский университет,
ул. Муравьева-Амурского, 35, Хабаровск, 680000 (Россия),
e-mail: galina.m.ya@mail.ru

Изучено влияние способов сушки листьев Fragaria orientalis Losinsk. на содержание флавоноидов и суммы окисляемых веществ. В сырье, высушенном способами конвективной и воздушно-теневой сушки, количество флавоноидов достоверно не различается. После воздушно-теневой сушки в сырье обнаруживается больше окисляемых веществ, чем после конвективной сушки.

Ключевые слова: земляника восточная (Fragaria orientalis Losinsk.), Восточная Сибирь и Дальний Восток, сушка лекарственного растительного сырья, флавоноиды, окисляемые вещества, дифференциальная спектрофотометрия.

\section{Введение}

В настоящее время в РФ официально признанным видом рода Fragaria L., семейства Rosaceae Juss. (розоцветные) является Fragaria vesca L. (земляника лесная). Официнальный вид по своему географическому распространению относится к евроазиатским бореальным видам. Его можно встретить на всей европейской части России (кроме районов Причерноморья, низовьев Волги и Крайнего Севера), на Кавказе, Средней Азии, Западной и Восточной Сибири. В некоторых районах Восточной Сибири и на Дальнем Востоке официнальный вид замещается близкородственным видом - Fragaria orientalis Losinsk. (земляника восточная) [1]. Специалистами по лекарственной флоре Дальнего Востока высказано предположение об идентичности фармакологических свойств обоих видов, основанное на местном применении дальневосточного викарианта [2-4].

В связи с этим на кафедре фармакогнозии и ботаники Дальневосточного государственного медицинского университета с 2003 г. проводится комплексное исследование з. восточной: изучаются химический состав сырья и его фармакологическая активность, решаются вопросы стандартизации сырья. Одним из этапов этих исследований является изучение вопросов заготовки сырья, в частности выбор оптимального способа сушки.

Мечикова Галина Ярославовна - доцент кафедры фармакогнозии и ботаники, кандидат фармацевтических наук, тел.: (4212) 32-64-26, e-mail: galina.m.ya@mail.ru

Степанова Татьяна Алексеевна - заведующий кафедрой фармакогнозии и ботаники, доктор фармацевтических наук, профессор,

тел.: (4212) 32-64-26, e-mail: natashavm@ mail.ru Матющенко Наталья Владимировна - доцент, кандидат фармацевтических наук,

тел.: (4212) 32-64-26, e-mail: natashavm@ mail.ru
Известно, что процессы, протекающие в растительном сырье во время сушки, характеризуются многогранностью и специфичны для каждого вида. Отечественные и зарубежные исследователи, изучающие вопросы консервации сырья, абсолютно единодушны, что определение параметров сушки сырья требует индивидуального подхода и оптимальные условия сушки для конкретного вида должны основываться на экспериментальных данных $[5,6]$.

\footnotetext{
* Автор, с которым следует вести переписку.
} 
Исследования, которые представлены в данной статье, выполнены с целью определения влияния способов сушки на содержание биологически активных веществ в листьях з. восточной и обоснования режимов сушки этого сырья для включения в Инструкцию по заготовке дальневосточного вида.

\section{Экспериментальная часть}

Объектами исследования служили листья 3. восточной. Изучение влияния условий сушки на содержание биологически активных веществ в сырье проводили в течение четырех вегетационных сезонов (2009, 2010, 2011 и 2012 гг.). Образцы сырья собирали в природных популяциях Хабаровского края. Заготовку сырья проводили в фазу массового цветения - начала плодоношения растений. Листья собирали с длиной черешка не более 1 см. Полученную партию сырого растительного материала тщательно перемешивали и делили на три пробы. Первую пробу использовали для оценки исходного содержания биологически активных веществ в свежем сырье. Вторая и третья пробы были предназначены для разных режимов сушки. Анализ свежих проб образцов, заготовленных в 2009-2011 гг., проводили не позднее чем через час после сбора. В эксперименте, спланированном в 2012 г., перед оценкой количества биологически активных веществ первую пробу фиксировали спиртом этиловом $95 \%$.

Сушку сырья 3. восточной осуществляли в соответствии с рекомендациями Инструкции по сбору и сушке официнального вида земляники [7]. Воздушно-теневую (естественную) сушку проводили в хорошо проветриваемых помещениях, рассыпав сырье тонким слоем на ткани и время от времени перемешивая. Конвективная (искусственная) сушка проводилась при температуре $45{ }^{\circ} \mathrm{C}$ в сушильной камере лабораторного типа «VENTICELL» (Чехия, BMT a.s.). Количество влаги в высушенных образцах составляло в среднем от 8 до $10 \%$.

После сушки в растительном сырье определяли содержание флавоноидов и окисляемых (дубильных) веществ. Кроме того, в эксперименте 2012 г. в образце, который высушивали естественным способом, была проведена оценка количества исследуемых веществ через 5 ч после начала сушки.

Флавоноиды были выбраны в качестве исследуемой группы по той причине, что стандартизация сырья официнального вида проводится по содержанию именно этой группы фенольного комплекса растения. Учитывая, что листья земляники используются в медицинской практике в виде настоя для внутреннего применения, нами было исследовано влияние способов сушки и на содержание суммы окисляемых веществ, извлекаемых водой.

Для определения содержания флавоноидов использовали дифференциальный спектрофотометрический метод, основанный на реакции комплексообразования флавоноидов с хлоридом алюминия. Измерение оптической плотности полученных комплексов флавоноидов проводили при длине волны 410 нм [8].

Окисляемые вещества определяли по методу ГФ XI, предложенному для определения дубильных веществ в растительных объектах [9]. Применение известной методики к исследуемому растительному объекту потребовало внесения некоторых изменений: в нашем случае навеска сырья составляла 0,5 г, аликвота для титрования 10 мл, титрование проводили не позднее чем через 5 минут после приготовления извлечения.

В работе применяли РСО рутина. Все использованные в эксперименте реактивы имели степень чистоты ч.д.а. Измерение оптических плотностей проводили на спектрофотометре UV-1700 (Shimadzu, Japan).

Определение каждой группы веществ проводили в трехкратной аналитической повторности. Содержание биологически активных веществ выражали в процентах в пересчете на абсолютно сухое сырье. Статистический анализ экспериментальных данных выполняли с применением программы Microsoft Office Excel 2010.

\section{Обсуждение результатов}

Полученные данные по влиянию способов сушки на количественное содержание биологически активных веществ, представлены в таблице. 
Содержание биологически активных веществ в свежих и высушенных листьях земляники восточной, \%

\begin{tabular}{c|c|c|c|c|c|c|c}
\hline \multicolumn{7}{c}{ Содержание биологически активных веществв листьях земляники восточной, \% } \\
\hline \multicolumn{7}{c}{ флавоноиды } & \multicolumn{4}{c}{ окисляемые вещества } \\
\hline 2009 г. & 2010 г. & 2011 г. & 2012 г. & 2009 г. & 2010 г. & 2011 г. & 2012 г. \\
\hline \multicolumn{7}{c}{ содержание биологически активных веществ в свежих (исходных) образцах } \\
\hline $2,36 \pm 0,03$ & $2,87 \pm 0,01$ & $3,39 \pm 0,02$ & $2,67 \pm 0,05$ & $13,6 \pm 0,18$ & $16,5 \pm 0,15$ & $15,9 \pm 0,01$ & $16,4 \pm 0,03$ \\
\hline \multicolumn{7}{c}{ содержание биологически активных веществ в образцах, высушенных воздушно-теневым способом } \\
\hline $2,84 \pm 0,01$ & $3,28 \pm 0,04$ & $3,79 \pm 0,05$ & $2,63 \pm 0,07$ & $19,8 \pm 0,18$ & $22,4 \pm 0,09$ & $22,9 \pm 0,17$ & $20,4 \pm 0,12$ \\
\hline \multicolumn{7}{c}{ содержание биологически активных веществ в образцах, высушенных конвективным способом } \\
\hline $2,86 \pm 0,03$ & $3,37 \pm 0,09$ & $3,91 \pm 0,02$ & $2,55 \pm 0,01$ & $18,4 \pm 0,27$ & $21,4 \pm 0,12$ & $20,8 \pm 0,13$ & $17,1 \pm 0,13$ \\
\hline
\end{tabular}

Как показала статистическая обработка результатов, оба способа сушки листьев з. восточной позволяют получить образцы сырья с практически одинаковым содержанием флавоноидов: между средними значениями количества флавоноидов в листьях, высушенных воздушно-теневым и конвективным способами, различия статистически незначимы с доверительной вероятностью $95 \%$ во всех четырех сериях эксперимента $\left(t_{\text {эксп }}=0,5 ; 0,9 ; 2,5 ; 1,19 ; t(P ; f)_{\text {крит }}=2,78\right)$. Изменения в содержании флавоноидов находятся в пределах погрешности методики.

В исследованиях, выполненных в 2009-2011 г., содержание флавоноидов в свежем сырье оказалось статистически достоверно ниже, чем в высушенных образцах. Полученные данные объясняются разницей выхода биологически активных веществ из свежего и сухого растительного сырья в соответствующие извлечения [10]. Подтверждением этому служат результаты, полученные в 2012 г. Фиксирование свежего сырья спиртом этиловым 95\% позволило разрушить протоплазму живых растительных клеток и тем самым обеспечить беспрепятственную диффузию веществ. Так, количество флавоноидов в свежем сырье, предва-

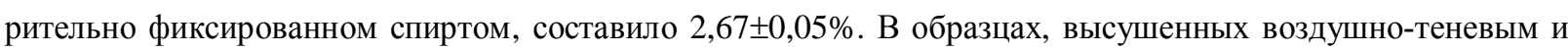
конвективным способами, количественное содержание этой группы фенольного комплекса растения оста-

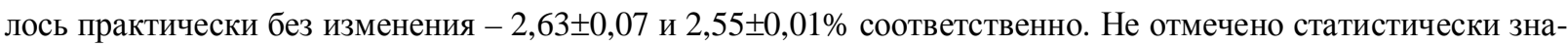
чимых изменений в количестве флавоноидов и через 5 ч после начала воздушно-теневой сушки $(2,65 \pm 0,03 \%)$.

Влияние способов сушки на содержание окисляемых веществ во всех партиях сырья четырех лет исследования проявляется в общей тенденции - количество этой суммы веществ статистически достоверно $(\mathrm{P}=95 \%)$ выше $\left(t_{\text {эксп }}=4,5 ; 6,7 ; 9,8 ; 18,4 ; t(P ; f)_{\text {крит }}=2,78\right)$ после естественной сушки. Разница между средними значениями суммы окисляемых веществ в образцах, высушенных конвективной (45 $\left.{ }^{\circ} \mathrm{C}\right)$ и воздушнотеневой сушкой, составила в наших исследованиях от 1 (2010 г.) до 3,3\% (2012 г.).

Полученные результаты позволяют предположить, что в процессе медленной потери влаги в листьях земляники восточной происходят ферментативные процессы (высвобождения из связанных форм, превращения и т.д.), которые в конечном итоге приводят к увеличению количества окисляемых веществ [5, 11]. Из данных, полученных в 2012 г. и представленных на рисунке, видно, что эти процессы происходят в первые часы сушки. Так, относительное увеличение содержания окисляемых веществ через 5 ч после начала воздушно-теневой сушки составило около $25 \%$ от их исходного количества в свежем сырье. При дальнейшей сушке не произошло значимых изменений в содержании суммы окисляемых веществ.

Изменение содержания окисляемых веществ в листьях з. восточной (образец 2012 г.) в процессе воздушно-теневой сушки:

1 - содержание окисляемых веществ в свежем сырье; 2 - содержание окисляемых веществ в сырье через 5 ч после начала сушки; 3 - содержание окисляемых веществ в высушенном сырье

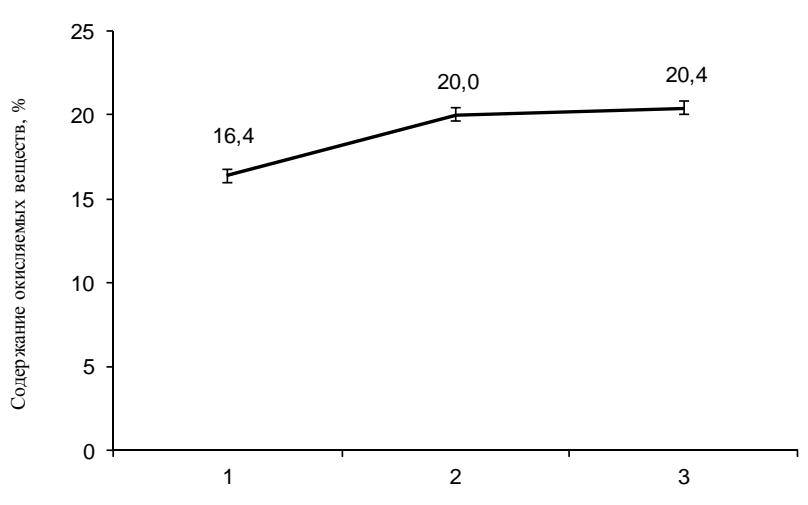


Использование сушки с искусственным нагревом $\left(45^{\circ} \mathrm{C}\right)$ останавливает каскад ферментативных процессов: статистически достоверное увеличение суммы окисляемых веществ в образце 2012, сбора, высушенном в сушильном шкафу, составило всего около 4\% $(17,1 \pm 0,13 \%)$ относительно содержания этих веществ в свежем сырье $(16,4 \pm 0,03 \%)$. Это можно объяснить тем, что использование нагрева во время сушки приводит к более быстрому испарению влаги и соответственно инактивации ферментных систем, способствующих большему выходу окисляемых веществ. Известно, что удаление влаги до 20\% уже снижает ферментную активность, а при содержании ее ниже 14\% деятельность ферментов прекращается [6].

Важным фармакопейным показателем внешних признаков растительного сырья, который во многом зависит от способа его сушки, является цвет. Нами не наблюдалось изменение цвета листьев. Следует отметить, что попытка использовать температуру сушки выше $50{ }^{\circ} \mathrm{C}$ приводила к изменению окраски сырья листья становились желтыми.

\section{Заключение}

Проведен анализ содержания флавоноидов и окисляемых веществ в листьях 3. восточной, высушенных двумя способами - воздушно-теневым и конвективным $\left(45^{\circ} \mathrm{C}\right)$. Эксперимент показал, что одинаковые условия сушки по-разному влияют на содержание флавоноидов и окисляемых веществ в сырье.

В результате исследований установлено, что оба способа сушки позволяют получить сырье, равноценное по содержанию флавоноидов. Поэтому с позиции сохранения этой группы веществ выбор варианта сушки не имеет значения.

В то же время режимы сушки влияют на содержание суммы окисляемых веществ в листьях 3. восточной. Воздушно-теневая сушка позволяет получить сырье с большим содержанием этой группы веществ, чем конвективная сушка. Исследование динамики воздушно-теневой сушки показало, что процессы увеличения количества окисляемых веществ проходят в первые часы. Однако следует отметить, что количественные колебания в содержании этой группы веществ в объединенной выборке двух способов сушки несущественны, несмотря на установленные статистически значимые различия $\left(t_{\text {эксп }}<t(P ; f)_{\text {крит }}\right)$ между их средними значениями в образцах, высушенных конвективной и воздушно-теневой сушкой. Подтверждением этому служат низкие значения коэффициентов вариации, которые составляют в четырех партиях сырья от 3 до 10\%. Это также говорит о том, что выбор способа сушки не принципиален.

Учитывая полученные результаты, мы рекомендуем использовать конвективную сушку с предварительным подвяливанием сырья в течение 5 ч. Такая комбинация вариантов сушки применительно к исследуемому объекту будет, на наш взгляд, оптимальной, так как позволит использовать преимущества и воздушно-теневой, и конвективной сушки. Во-первых, подвяливание сырья способствует увеличению выхода биологически активных веществ из листьев з. восточной. Во-вторых, использование конвективной сушки интенсифицирует процесс заготовки в промышленных масштабах, потому что этот способ сушки, бесспорно, приводит к более быстрому высушиванию сырья, чем воздушно-теневой. И, наконец, с учетом того, что конвективная сушка заметно подавляет микрофлору [6], использование ее в процессе консервации сырья дает дополнительные преимущества.

Результаты проведенных исследований и соответствующие рекомендации будут включены в проект Инструкции по сбору и сушке листьев з. восточной.

\section{Список литературы}

1. Черепанов С.К. Сосудистые растения России и сопредельных государств (в пределах бывшего СССР). Русское издание. СПб., 1995. 992 с.

2. Кадаев Г.И., Фруентов Н.К. Дикорастущие лекарственные растения Приамурья. Хабаровск, 1968. 191 с.

3. Фруентов Н.К. Лекарственные растения Дальнего Востока. Хабаровск, 1972. 400 с.

4. Шретер А.И. Лекарственная флора Советского Дальнего Востока. М., 1975. 327 с.

5. Бузук Г.Н. Влияние температуры сушки на компонентный состав и количественное содержание алкалоидов в сырье некоторых видов лекарственных растений // Растительные ресурсы. 1991. Т. 27, №3. С. 100-108.

6. Müller J., Heindl A. Drying of medicinal plants // Medicinal and Aromatic Plants. Springer, 2006. Pp. 237-252.

7. Правила сбора и сушки лекарственных растений: (сборник инструкций). М., 1985. 328 с.

8. Мечикова Г.Я., Загузова Е.В., Степанова Т.А. Определение суммы флавоноидов в листьях земляники восточной // Дальневосточный медицинский журнал. 2005. №2. С. 78-81. 
9. Государственная фармакопея СССР: Общие методы анализа. МЗ СССР. 11-е изд., доп. М., 1987, вып. 1. 336 с.

10. Минина С.А., Каухова И.Е. Химия и технология фитопрепаратов: учеб. пособие. М., 2009. 560 с.

11. Стуккей К.Л., Терентиенко Г.М. Исследования сушки соцветий пижмы // Химико-фармацевтический журнал. 1983. Т. 17, №11. С. 1331-1334.

Поступило в редакиию 17 апреля 2012 г.

После пераработки 26 января 2013 г.

Mechikova G.Y. ${ }^{*}$ Stepanova T.A., Matyushchenko N.V. EFFECTS OF DRYING METHODS ON MICRONUTRIENTS FOUND IN LEAVES OF FRAGARIA ORIENTALIS LOSINSK

Far Eastern State Medical University, ul. Murav'eva-Amurskogo, 35, Khabarovsk, 680000 (Russia),

e-mail: galina.m.ya@mail.ru

The study was taken to determine the effects of drying methods on quantity of flavonoids, polyphenolic compounds and tanning agents found in leaves of Fragaria orientalis Losinsk. There was found no difference in amount of flavonoids in plants dried in oven and in the open air (in shade). Slight changes were discovered in the quantity of polyphenolic compounds and tanning arents found in leaves of Fragaria orientalis Losinsk. depending on the drying metod.

Keywords: Fragaria orientalis Losinsk., Eastern Siberia and the Far East, drying of herbs, changes in amount of micronutrients, flavonoids, polyphenolic compounds, tanning agents, spectrophotometry.

\section{References}

1. Cherepanov S.K. Sosudistye rasteniia Rossii i sopredel'nykh gosudarstv (v predelakh byvshego SSSR). Russkoe izdanie. [Vascular plants of Russia and adjacent states (the former USSR). Russian edition.]. St Petersburg, 1995, 992 p. (in Russ.).

2. Kadaev G.I., Fruentov N.K. Dikorastushchie lekarstvennye rasteniia Priamur'ia. [Wild herbs Amur]. Khabarovsk, 1968, 191 p. (in Russ.).

3. Fruentov N.K. Lekarstvennye rasteniia Dal'nego Vostoka. [Medicinal Plants of the Far East]. Khabarovsk, 1972, 400 p. (in Russ.).

4. Shreter A.I. Lekarstvennaia flora Sovetskogo Dal'nego Vostoka. [Medicinal flora of the Soviet Far East.]. Moscow, 1975, 327 p. (in Russ.).

5. Buzuk G.N. Rastitel'nye resursy, 1991, vol. 27, no. 3, pp. 100-108. (in Russ.).

6. Müller J., Heindl A. Medicinal and Aromatic Plants. Springer, 2006. Pp. 237-252.

7. Pravila sbora i sushki lekarstvennykh rastenii: (sbornik instruktsii). [The collection and drying of herbs (a collection of instructions).]. Moscow, 1985, 328 p. (in Russ.).

8. Mechikova G.Ia., Zaguzova E.V., Stepanova T.A. Dal'nevostochnyi meditsinskii zhurnal, 2005, no. 2, pp. 78-81. (in Russ.).

9. Gosudarstvennaia Farmakopeia SSSR: Obshchie metody analiza. MZ SSSR. 11-izd., dop. [State Pharmacopoeia of the USSR: General methods of analysis]. Moscow, 1987, no. 1, 336 p. (in Russ.).

10. Minina S.A., Kaukhova I.E. Khimiia i tekhnologiia fitopreparatov. [Chemistry and Technology of medicines]. Moscow, 2009, 560 p. (in Russ.).

11. Stukkei K.L., Terentienko G.M. Khimiko-farmatsevticheskii zhurnal, 1983, vol. 17, no. 11, pp. 1331-1334. (in Russ.).

Received April 17, 2012

Revised January 26, 2013

\footnotetext{
* Corresponding author.
} 
